
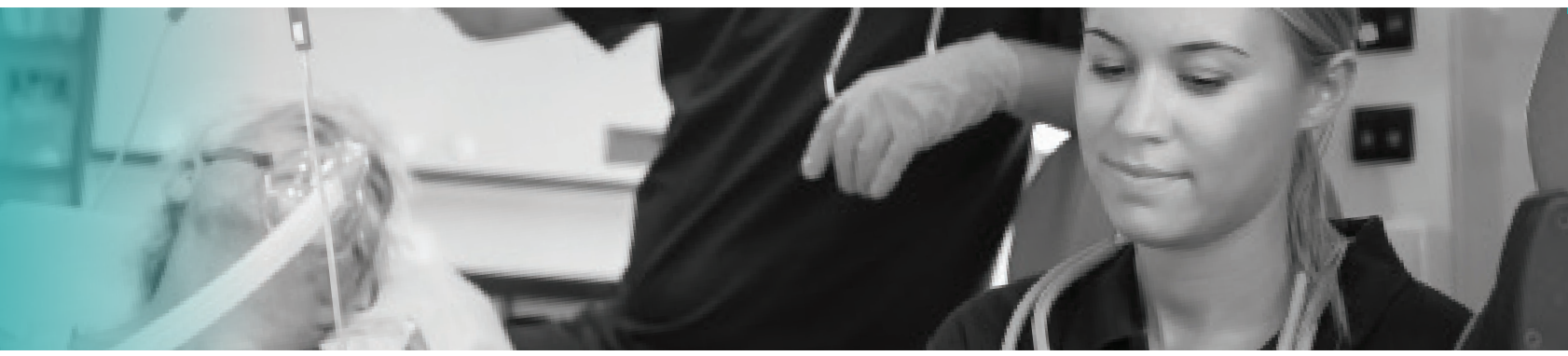

Volume 15 | Issue 1 | Article 2
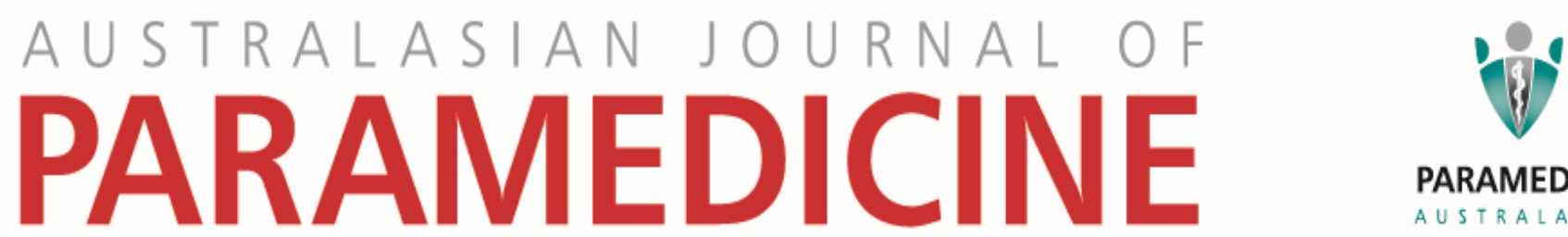

PARAMEDICS

Evaluating the potential of iPads to actively engage paramedicine students in an authentic learning experience

Georgia Clarkson

Australian Catholic University, Melbourne, Victoria 


\title{
Research
}

\section{Evaluating the potential of iPads to actively engage paramedicine students in an authentic learning experience}

\author{
Georgia Clarkson BA, DipEd, DipAmbPara, GCTE, MEd, PhD is a Senior Lecturer ${ }^{1}$
}

Affiliation:

${ }^{1}$ Australian Catholic University, Melbourne, Victoria

\section{Abstract}

\section{Introduction}

Paramedicine students are required to develop the skills of assessing and managing clinical presentations to prepare them for practice. Active learning strategies that are student centred, facilitate collaboration and mirror workplace practices can assist the development of requisite skills. iPads provide a portable means of integrating audiovisual material into these clinical scenarios. Use of such material has the potential to add a degree of authenticity to this environment and require students to play a more active part in their learning.

\section{Methods}

This study introduced the 'iPad-SFS', a system for using iPads as a platform for introducing audiovisual material into practical classes, as a means of promoting active learning. Students completed a Likert scale survey inviting quantitative and qualitative feedback to evaluate the impact of this intervention on their learning experience.

\section{Results}

The data indicated using iPads promoted engagement, enhanced realism, promoted a more collaborative and authentic learning experience and improved critical thinking.

\section{Conclusion}

Overall, the iPad based system impacted positively on student learning experience. Health professional educators in paramedicine should consider the use of system similar to iPad-SFS in practical classes.

Keywords:

iPads; active learning; collaborative learning; critical thinking; authenticity; simulation 


\section{Introduction}

Having transitioned from a vocational education model only in the past two decades, university education for paramedics is relatively new both in Australia and internationally (1). As paramedics are commonly the first link in the continuum of health care (2), it is imperative that graduates are well prepared for the practice of patient assessment and care. This means that students need to develop standard graduate attributes such as critical thinking and clinical skills, and be able to apply these within a dynamic and challenging environment. Undergraduate paramedicine programs deliver a significant amount of content through practical classes. In these classes students are required to use clinical and communication skills to acquire and interpret key information and initiate treatment.

As a newcomer, paramedicine is still trying to 'chisel out its identity' in the higher education discourse (3) and is yet to develop a 'signature pedagogy' (4) to prepare students for professional practice in the same manner as more established disciplines. Despite this, paramedic programs have some core characteristics that are typically adopted to assist students to think critically, use clinical evidence and collaborate.

Critical thinking has been defined in a number of different ways $(5,6)$ and despite variations, key components include seeking and evaluation of evidence and the application of theory to solve problems on the basis of evidence gathered (7). It therefore promotes a systematic and structured approach to problem solving based on evidence. Although there is no universally established process which defines the series of activities paramedics perform in the prehospital context (8), within all health disciplines the ability to successfully provide care is dependent on the principles of critical thinking and decision-making (9). Therefore, systems that promote development of this type of thinking tend to feature in paramedicine curricula.

Adopting learning systems where students acquire and appraise a range of evidence within the classroom environment can potentially increase the amount of active learning a student is engaged in. They can also contribute to bridging the theory-practice gap by more authentically representing the role of a paramedic (10). While providing active and authentic learning experiences for students is highly desirable, practical constraints of learning environments often result in 'pre-interpreted' clinical evidence being provided to students engaged in problem solving. A system that increases the amount of 'raw' clinical evidence available to students may therefore more actively engage students in processes of interpretation and possibly improve critical thinking.
As paramedics work in small teams, the ability to collaborate and communicate is paramount. Strategies that assist students to develop these skills can be of value in providing an authentic learning experience. Peer teaching models have been shown to have value in higher education in general (11) and within paramedic education programs specifically (12). A system that provides a platform for collaborative learning can therefore be of value in teaching paramedic students.

Students learn better when engaged in the learning process (13) and activities or discussion that emphasise higher order thinking promote better quality learning (14). Further, constructivist informed active learning strategies which allow the learner to drive the acquisition of new knowledge, produce a better quality of learning than teacher centred models (1417). In the context of clinical programs, it has been shown that active learning models assist students to develop both critical thinking skills (18) and clinical competencies (19). This principle has underpinned the use of simulation in clinical programs.

Simulation has an integral role in paramedic education $(20,21)$ and a range of models have been used to facilitate this type of learning. One typical model occurs in classes where a few students 'demonstrate' their approach to solving a clinical problem while remaining class members observe. Some evidence indicates that students learn from observing in this model of classroom practice (22-24). A second model of learning adopted requires students to work through clinical problems concurrently in small groups. There is evidence attesting to the benefits of the more participatory active style of learning within this model, particularly in relation to psychomotor skills necessary for clinical practice (19).

While a range of simulation equipment is generally available, even the most advanced simulators stop short of providing a 'life-like' experience, creating a gap in terms of the authenticity of the learning experience. Student experiences in the practical laboratory are therefore commonly facilitated by teachers presenting a clinical problem by providing clinical values in written or verbal format. In the field these values would need to be acquired and interpreted therefore students are engaged in a learning process that is less active than the role they would undertake as a paramedic in the field.

Since their release in 2010, iPads have been embraced widely within the education sector, however their impact on student engagement and learning remains underexplored (25). Some studies have found that use of iPads for educational purposes can enhance learning experiences but not necessarily improve learning outcomes (26). Other evidence indicates that using mobile platforms such as iPads may help students to engage more fully (27-29). 
iPads can provide 'point-of-care access to resources' and promote evidence-based decision making (30), a fundamental feature of most contemporary health programs (31). Undergraduate paramedicine classes take place in an environment that is highly active and mobile. iPads can meet the needs of this group of learners as they possess the physical characteristics required to facilitate this active and collaborative model of learning (25).

\section{The iPad-SFS}

The iPad scenario facilitation system (iPad-SFS) active learning model adopted in this research was introduced to support the needs of paramedic students by giving them primary responsibility for their own learning (32). It drew on evidence showing that an active style of learning is more engaging, and therefore effective, than more passive models (33). The iPad-SFS strategy required students to engage in more thinking when completing learning activities than they would have in its absence (34).

The model of classroom practice adopted at the site of the study meant that students completed clinical scenarios in small groups. Before introducing iPad-SFS, active learning was facilitated using a printed document containing a series of patient observations, clinical descriptors and historical information. Groups of four students used this printed information to guide the clinical scenario. Two group members played the role of paramedic crew and the remaining students played other roles including patient, observer and facilitator. Students rotated through these roles as they progressed through a study period. Several of these groups of four worked concurrently within the laboratory space guided by a member of the academic staff.

The printed document that guided scenarios was used in conjunction with a range of patient simulation equipment. Although patient simulators are able to generate a large range of clinical information, even the most advanced are limited. As a result, clinical information that would be obtained by visual or auditory means when dealing with a real patient was provided in text format. The type of information commonly related to descriptions of wounds, sounds, scene descriptions and mechanisms of injury.

The use of iPad-SFS enabled the step of pre-interpretation to be omitted in a number of instances. Instead of describing information in a text format, students were provided with links to audiovisual resources accessible through a Wi-Fi connected iPad. No specialised software was required as links were embedded into portable document format (PDF) and made available to students through their existing learning management system. These links contained images, sounds and video footage of clinical and environmental aspects of the scenario students were attempting. On accessing linked information, students were required to evaluate it within the context of the scenario presented to them. This research aims to evaluate the effectiveness of the iPad-SFS in improving engagement, collaboration, authenticity and critical thinking of paramedic students in the practical laboratory environment.

\section{Methods}

\section{Research process}

The site of this study was one campus of a multi-campus Australian university. iPad-SFS was piloted in paramedicine laboratories in one Year 2 unit of study delivered over one 12week semester. All students used the iPad-SFS to guide them in completing clinical scenarios.

Following ethics approval, students were invited to complete a 14-item Likert-scale questionnaire related to their experience of using iPad-SFS. A 5-point Likert scale was used. Participants were presented with a series of statements and were requested to select 5 where they strongly agree, 4 when they agreed, 3 for neutral, 2 where they disagreed and 1 where they strongly disagreed. The questionnaire focused on student experience in the areas of user friendliness, engagement, collaboration, realism and critical thinking. A free text section was included after each question.

\section{Participants}

The survey was administered to a cohort of 92 students at the completion of the semester. Eighty-four questionnaires were returned and all were fully completed ( $91 \%$ return rate).

\section{Analysis}

SPSS software was used to analyse quantitative data. To identify statistically significant results items underwent Chisquare tests to determine whether the introduction of iPadSFS improved the students' view of their learning experience in relation to engagement, collaboration, authenticity and critical thinking when compared to the previous learning model. Values were statistically significant with a $p$ value of $<0.001$.

\section{Results}

Overall, participants indicated that in some of the five focus areas of user friendliness, engagement, collaboration, realism and critical thinking, iPad-SFS improved their experience within practical classes. Responses related to each of these themes are described below.

\section{Student engagement}

The majority of students felt that iPad-SFS was easy to use (Q1) and that they would like to continue using iPad-SFS in clinical classes (QN2) (Table 1). 
Table 1. User friendliness

\begin{tabular}{|c|l|c|c|}
\hline Number & \multicolumn{1}{|c|}{ Statement } & Median & Interquartile range \\
\hline 1 & $\begin{array}{l}\text { I found the iPads easy to use in the context of practical } \\
\text { classes }\end{array}$ & 5 & 1 \\
\hline 2 & $\begin{array}{l}\text { I would like to use iPads in paramedic practical classes in the } \\
\text { future }\end{array}$ & 5 & 1 \\
\hline
\end{tabular}

Table 2. Student engagement

\begin{tabular}{|c|l|c|c|}
\hline Number & \multicolumn{1}{|c|}{ Statement } & Median & Interquartile range \\
\hline 3 & $\begin{array}{l}\text { Using iPads in practical classes enabled me to become more } \\
\text { involved in the classes }\end{array}$ & 4 & 1 \\
\hline 4 & $\begin{array}{l}\text { I was able to use class time more effectively using the iPad } \\
\text { model than previous models }\end{array}$ & 4 & 1 \\
\hline 5 & $\begin{array}{l}\text { I participated in more scenarios over the semester using the } \\
\text { iPad model than I had previously in similar classes }\end{array}$ & 4 & \\
\hline 6 & $\begin{array}{l}\text { I felt that iPad use freed up the class facilitator from other } \\
\text { tasks, therefore I was able to engage with them more when } \\
\text { required }\end{array}$ & 4 & \\
\hline
\end{tabular}

In the qualitative data, one student indicated 'iPads have been a very useful learning tool and I feel they have contributed positively to our prac classes this semester'.

Students indicated that they found iPad-SFS easy to use and valuable to tap into resource and reference materials. Several students highlighted that using iPad-SFS 'is more environmentally friendly'. Many comments highlighted the efficiency that some students felt iPad-SFS afforded in classes. Less positive responses within the qualitative data indicated that iPad-SFS was 'just an electronic version of paper resources' and therefore provided no real advantage over the pre-existing model.

\section{Student engagement}

Most participants indicated that iPad-SFS enabled them to become more involved in classes (QN3), use class time more effectively (QN4) and participate in a greater number of learning activities (QN5) (Table 2). Participants also felt they were more able to engage with the teacher where required as they were 'freed up' by virtue of having iPad-SFS available to facilitate scenarios (QN6).

Participants stated that using iPad-SFS was 'interesting' and 'straightforward' as 'most people had previous experience with iPads'. Participants described classes as 'more engaging' and stated that they 'involved everyone in things that otherwise wouldn't have'. One participant stated that the ability to 'zoom in on images and watch videos to give a greater understanding' was appealing and engaging. Further responses indicated that engagement was improved as a result of 'having all info available through an audio/video source' and being 'exposed to more information'.

In addition to improved engagement with learning activities, participants indicated that they felt increased engagement with other students and academic staff when they were required. It was suggested that the increased engagement with academic staff was due to them being freed up as a result of iPad-SFS. This view was not unanimous however, with one participant stating that just because staff became more available 'it didn't mean we could engage more'. 


\section{Collaboration}

Responses to questions shown in Table 3 indicated a majority of participants felt that using iPad-SFS meant they collaborated more with their peers both when completing scenarios and in the process of debriefing (QN7, QN8). Several participants made comments such as iPad-SFS 'allowed scenarios to be more of a group activity'. One participant observed that classes were 'more interactive as people were handing the iPad around and discussing instead of sitting there... not sharing ideas'. Participants also highlighted that the iPads were 'helpful to answer questions when a teacher was busy'. This meant that when there was conjecture within groups related to various clinical conditions students were able to collaborate independently.

Evidence suggested that the nature of the group activity fostered by iPad-SFS meant that addressing the clinical issue presented in classes 'required effective communication'. Some participant observations indicated that the enhanced peer-topeer communication meant strengthened peer relationships and collaboration skills. Data showed that the 'ability to check answers on the internet helped debriefing'. The camera function on the iPad enabled some students 'to record and watch scenarios to aid with the debriefing' and this was seen as a favourable aspect of iPad-SFS.

\section{Authenticity}

Questions related to the theme of authenticity are shown in Table 4. Participants tended to support the premise that integrating iPad-SFS into clinical scenarios improved realism (QN9) however, there was no evidence to indicate that this assisted them to prepare for similar situations in the workplace (QN10). Participants indicated that this improved realism did not evoke a more emotive response (QN11).

Some participants also felt that iPad-SFS was 'useful for creating a real-life approach' and improved realism of scenarios as it facilitated an 'experience' which was 'a closer match to an actual on road scenario'. Several participants felt that the ability to interpret a range of resource material made it seem closer to real life as it 'provided additional stimulus which enhanced' classes. Participants suggested that this enhancement was attributable to IPad-SFS facilitating scenarios that were 'easier and more realistic' as students were able to 'see things you wouldn't usually be able to'.

Table 3. Collaboration

\begin{tabular}{|c|l|c|c|}
\hline Number & \multicolumn{1}{|c|}{ Statement } & Median & Interquartile range \\
\hline 7 & $\begin{array}{l}\text { Using the information on the iPad provided me with a better } \\
\text { guide to debriefing scenarios with my peers than previous } \\
\text { paper based resources }\end{array}$ & 4 & 1.5 \\
\hline 8 & $\begin{array}{l}\text { I felt more like I was learning in collaboration with my peers } \\
\text { when using iPads than when using paper-based systems }\end{array}$ & 4 & 1 \\
\hline
\end{tabular}

Table 4. Authenticity

\begin{tabular}{|c|l|c|c|}
\hline Number & \multicolumn{1}{|c|}{ Statement } & Median & Interquartile range \\
\hline 9 & Having visual and audio material available felt more realistic & 4 & 1 \\
\hline 10 & $\begin{array}{l}\text { I feel better prepared for real-life situations as iPads provided } \\
\text { increased realism in completing scenarios in classes }\end{array}$ & 3 & 1 \\
\hline 11 & $\begin{array}{l}\text { Having access to audio-visual resources using iPads in } \\
\text { practical classes evoked more of an emotional response from } \\
\text { me than when using paper-based systems }\end{array}$ & 3 & 2 \\
\hline
\end{tabular}


Clarkson: Evaluating the potential of iPads to engage paramedicine students

Australasian Journal of Paramedicine: 2018;15(1)

Table 5. Critical thinking

\begin{tabular}{|c|l|c|c|}
\hline Number & \multicolumn{1}{|c|}{ Statement } & Median & Interquartile range \\
\hline 12 & $\begin{array}{l}\text { The use of iPads in paramedic practical classes this semester } \\
\text { required me to think more in order to complete clinical } \\
\text { scenarios }\end{array}$ & 3 & 1 \\
\hline 13 & $\begin{array}{l}\text { Including audio-visual material in scenarios made them more } \\
\text { challenging than previous ways of facilitating scenarios }\end{array}$ & 3 & 1 \\
\hline 14 & $\begin{array}{l}\text { Ifeel better prepared for my clinical exam due to using iPads in } \\
\text { practical classes }\end{array}$ & 3 & 1 \\
\hline
\end{tabular}

Some participants indicated that the completion of scenarios using iPad-SFS evoked a more emotional response than using the paper-driven model 'when photos and/or videos' were used. The response elicited through exposure to clinical stimuli more closely resembling what would be encountered in the field was felt by some students to be more authentic. Less favourably, participants noted that iPad-SFS made classes 'more realistic, not more challenging' and that while iPad-SFS enhanced realism it did not 'compare to real life scenarios and human reactions'.

\section{Critical thinking}

Responses related to critical thinking are shown in Table 5. In relation to this theme, there was no evidence that participants felt using audiovisual resources required them to think more (QN12) or that using iPad-SFS was more challenging (QN13). There was no evidence to indicate that participants felt better prepared for their clinical examinations at the end of the semester (QN14).

Some participants indicated that they felt iPad-SFS improved critical thinking as it 'gives more info... to work out'. Some of the additional information that required more student interpretation and therefore increased the degree of critical thinking required included 'images of electrocardiograms [which] helped to engage more thinking' and 'videos/pictures of scene/patient' which prompted more thought than "just being told about the patient'. One participant pointed out that the iPad-SFS 'helped with clinical approach', which is in essence a critical thinking process.

\section{Discussion}

iPad-SFS engaged students using web links to introduce additional functionality to an existing approach. Evidence obtained through this research indicated that participants declared a desire to continue using the system. It was shown that iPad-SFS fostered participation and collaboration, both of which have been shown to significantly contribute to better student outcomes in the practical teaching space (35). Findings from this study are consistent with studies that show students have a preference for learning platforms that are familiar to them as they find them more engaging (36). While it would be simplistic to assume that all students can be labelled 'digital natives' (37), the majority of students who participated were school leavers and in the age bracket that grew up using digital technology.

This study found that iPad-SFS was beneficial in engaging students with content, peers and staff. This 'triad' of engagement is a critical aspect of student retention $(38,39)$. As retention of students is an issue locally (40) and internationally (41), engagement is an increasingly important focus in higher education discourse (42). Peer engagement may assist in the development of social networks and engender a sense of belonging and ongoing support (43). In turn, this sense of belonging can lead to collaboration and deeper understanding of aspects of the curriculum.

Within the growing body of research into cooperative learning (44) it is accepted that students who learn together develop superior communication skills and are therefore better prepared to work in a context reliant on such skills (45). Studies conducted in the context of paramedicine echo this, indicating that collaboration with peers has a positive impact (12), in particular on communication and problem-solving skills of students (46). The long-term value of improving inter-peer communication skills is also favourable for graduates who aim to work in small interdependent teams. As participants also indicated, improved engagement with teaching staff and the classroom engagement promoted by iPad-SFS, may contribute to the retention of students.

Within the field of paramedicine there is conjecture related to the ability of higher education providers to adequately prepare graduates for practice (47) in a market of increasing competition for graduate positions (48). This means that in 
Clarkson: Evaluating the potential of iPads to engage paramedicine students Australasian Journal of Paramedicine: 2018;15(1)

order to better prepare for a work environment, students and educators need to capitalise on all available learning opportunities $(10,49)$. It is therefore vital that opportunities to improve critical thinking in the classroom environment are fully exploited so that this fundamental aspect of the role of a health practitioner (9) and foundational component of paramedic practice (50) is developed by students. Evidence showed no improvement in critical thinking as a result of using iPad-SFS despite some findings showing that it evoked more realism in the classroom.

Realism is considered an essential element of simulation practice (51) and enhanced realism has been found to better prepare students for complex and challenging roles (52).

Further, some studies indicate that participation in authentic simulated learning experiences improves student confidence and competence (53). Following from this, simulation is widely used within paramedic education although practices vary widely from one education provider to another (20). While it can be argued that higher 'fidelity' experiences require students to solve more authentic problems, this is not always achievable within the context of operational constraints. Conversely, it has also been shown that constructively aligned low-fidelity simulation strategies, such as iPad-SFS, can be the most effective in facilitating authentic student learning (54). Some evidence from this study indicated that iPad-SFS provided a cost effective and replicable way to enhance realism in practical classes, therefore improving authenticity within the context of operational constraints.

Finally, it is held that managing emotional situations is integral to the work of paramedics and undergraduate programs need to prepare students to perform this type of work effectively (55). Evidence in this research showed iPad-SFS could evoke a more emotional response than previous approaches for some students in some instances, therefore assisting students to prepare for the work of a paramedic.

\section{Sustainability}

This intervention provided a low cost and sustainable means of facilitating classes. iPads continue to be available for use in practical classes. No additional costs are associated with the continued use of this system aside from potential costs associated with repair. Additional costs may need to be met in the case of theft, loss or permanent damage, although this is unlikely. Savings on stationery and printing marginally offset the initial cost.

\section{Limitations}

This study was limited to one cohort of students completing a specific unit of study over one semester. Although evidence from this study indicates iPad-SFS contributed in a positive way to the student experience, further research into its value and application is required to fully explore its potential.

\section{Conclusion}

iPad-SFS demonstrated positive results in providing an easily replicable, cost effective and sustainable means of linking the classroom experience more closely to that of the real world. Feedback from participants indicated that it had a positive impact on the overall student experience. This is critical in a climate where a smooth transition to the workplace depends on skills and theory development during undergraduate programs. It is also significant in an increasingly competitive employment market for paramedic graduates. Health professional educators in paramedicine should consider the use of systems similar to iPad-SFS in practical classes.

\section{Acknowledgements}

The author would like to acknowledge the technical and academic staff teams operating in the practical laboratory at the Melbourne campus of Australian Catholic University for assisting with the set up and maintenance of iPad-SFS.

\section{Conflict of interest}

The author declares no competing interests. The author of this paper has completed the ICMJE conflict of interest statement.

\section{Funding}

This project was funded by a faculty teaching and learning grant.

\section{References}

1. Devenish AS, Clark MJ, Flemming M. Experiences in becoming a paramedic: the professional socialization of university qualified paramedics. Creat Educ 2016;7:786801.

2. O'Meara PF, Tourle V, Stirling C, Walker J, Pedler

D. Extending the paramedic role in rural Australia: a story of flexibility and innovation. Rural Remote Health 2012;12:1978.

3. Lazarsfeld-Jensen A. Telling stories out of school: experiencing the paramedic's oral traditions and role dissonance. Nurse Educ Pract 2014;14:734-9.

4. Boitel CR, Fromm LR. Defining signature pedagogy in social work education: learning theory and the learning contract. J Soc Work Educ 2014;50:608-22.

5. Johnson M, Boyd L, Grantham H, Eastwood K. Paramedic principles and practice ANZ: a clinical reasoning approach. Chatswood, NSW: Elsevier; 2015.

6. Petress K. Critical thinking: an extended definition. Education 2004;124:461. 


\section{References (continued)}

7. Chan ZC. A systematic review of critical thinking in nursing education. Nurse Educ Today 2013;33:236-40.

8. Carter $\mathrm{H}$, Thompson J. Defining the paramedic process. Aust J Prim Health 2015;21:22-6.

9. Linwood R, Day G, FitzGerald G, Oldenburg B. Quality improvement and paramedic care. Int J Health Care Qual Assur 2007;20:405-15.

10. Michau R, Roberts S, Williams B, Boyle M. An investigation of theory-practice gap in undergraduate paramedic education. BMC Med Educ 2009;9:23.

11. Williams B, Nguyen D. Near-peer teaching in paramedic education: a repeated measures design. Innov Educ Teach Int 2016;1-10.

12. Fox M, Winship C, Williams W, et al. Peer-assisted teaching and learning in paramedic education: a pilot study. International Paramedic Practice 2015;5:22-8.

13. Moyer SM. Large group simulation: using combined teaching strategies to connect classroom and clinical learning. Teach Learn Nurs 2016;11:67-73.

14. Freeman S, Eddy SL, McDonough M, et al. Active learning increases student performance in science, engineering, and mathematics. Pro Natl Acad Sci U S A 2014;111:8410-5.

15. Brandon AF, All AC. Constructivism theory analysis and application to curricula. Nurs Educ Perspect 2010;31:89-92.

16. Slavich GM, Zimbardo PG. Transformational teaching: theoretical underpinnings, basic principles, and core methods. Educ Psychol Rev 2012;24:569-608.

17. Tirrell T, Quick D. Chickering's Seven Principles of Good Practice: student attrition in community college online courses. Community College Journal of Research and Practice 2012;36:580-90.

18. Kim K, Sharma P, Land SM, Furlong KP. Effects of active learning on enhancing student critical thinking in an undergraduate general science course. Innov High Educ 2013;38:223-35.

19. Shin S, Park J, Kim J. Effectiveness of patient simulation in nursing education: meta-analysis. Nurse Educ Today 2015;35:176-82.

20. McKenna KD, Carhart E, Bercher D, Spain A, Todaro J, Freel J. Simulation use in paramedic education research (SUPER): a descriptive study. Prehosp Emerg Care 2015;19:432-40.

21. Williams B, Abel C, Khasawneh E, Ross L, Levett-Jones T. Simulation experiences of paramedic students: a crosscultural examination. Adv Med Educ Pract 2016;7:181-6.

22. Bloch SA, Bloch AJ. Simulation training based on observation with minimal participation improves paediatric emergency medicine knowledge, skills and confidence. Emerg Med J 2015;32:195-202.

23. Kaplan BG, Abraham C, Gary R. Effects of participation vs. observation of a simulation experience on testing outcomes: implications for logistical planning for a school of nursing. Int J Nurs Educ Scholarsh 2012:9:1-15.

24.Scherer YK, Foltz-Ramos K, Fabry D, Chao YY. Evaluating simulation methodologies to determine best strategies to maximize student learning. J Prof Nurs 2016;32:349-57.

25. Diemer T, Fernandez E, Streepey J. Student perceptions of classroom engagement and learning using iPads. J Teach Learn Technol 2012;1:13-25.

26. Nguyen L, Barton SM, Nguyen LT. iPads in higher education-hype and hope. Br J Educ Technol 2015;46:190203.

27.Davies R, Dean D, Ball N. Flipping the classroom and instructional technology integration in a college-level information systems spreadsheet course. Educ Tech Res Dev 2013:61:563-80.

28. Davies M. Using the Apple iPad to facilitate student-led group work and seminar presentation. Nurse Educ Pract 2014;:14:363-7.

29. George P, Dumenco L, Doyle R, Dollase R. Incorporating iPads into a preclinical curriculum: a pilot study. Med Teach 2013;35:226-30.

30. Brown J, McCrorie P. The iPad: tablet technology to support nursing and midwifery student learning: an evaluation in practice. Comput Inform Nurs 2015;33:93-8.

31. O'Meara PF, Maguire B, Jennings P, Simpson P. Building an Australasian paramedicine research agenda: a narrative review. Health Res Policy Syst 2015;13:79.

32. McGarry BJ, Theobald K, Lewis PA, Coyer F. Flexible learning design in curriculum delivery promotes student engagement and develops metacognitive learners: an integrated review. Nurse Educ Today 2015;35:966-73.

33. Miller CJ, Metz MJ. A comparison of professional-level faculty and student perceptions of active learning: its current use, effectiveness, and barriers. Adv Physiol Educ 2014;38:246-52.

34. Roehl A, Reddy S, Shannon G. The flipped classroom: An opportunity to engage millennial students through active learning strategies. J Fam Consum Sci 2013;105:44-9.

35. Senette L, O'Malley M, Hendrix T. Passing the baton: using simulation to develop student collaboration. Clin Simul Nurs 2013;9:e39-46.

36. Harris L. Secondary teachers' conceptions of student engagement: engagement in learning or in schooling? Teach Teach Educ 2011;27:376-86.

37. Bennett S, Maton K, Kervin L. The 'digital natives' debate: a critical review of the evidence. $\mathrm{Br} J$ Educ Technol 2008;39:775-86.

38. Pearce J, Down B. Relational pedagogy for student engagement and success at university. Aust Educ Res 2011;38:483-94.

39. Gunuc S, Kuzu A. Student engagement scale: development, reliability and validity. Assess Eval High Educ 2015;40:587610. 


\section{References (continued)}

40. Crosling G, Heagney M, Thomas L. Improving student retention in higher education: improving teaching and learning. Australian Universities Review 2009;51:9-18.

41. Burkholder GJ, Holland N. International perspectives on retention and persistence. High Learn Res Commun 2014:4:3-10.

42. Rocca K. Student participation in the college classroom: an extended multidisciplinary literature review. Commun Educ 2010;59:185-213.

43. Masika R, Jones J. Building student belonging and engagement: insights into higher education students' experiences of participating and learning together. Teach High Educ 2016;21:138-50.

44. Hardman J. Tutor-student interaction in seminar teaching: implications for professional development. Active Learn High Educ 2016;17:63-76.

45. Levett-Jones T, Gilligan C, Lapkin S, Hoffman K. Interprofessional education for the quality use of medicines: designing authentic multimedia learning resources. Nurse Educ Today 2012;32:934-8.

46. Willis S. Student paramedics' perceptions of action learning: a mixed-method study. J Paramedic Prac 2014;6:626-32.

47. Thompson J, Grantham H, Houston D. Paramedic capstone education model: building work ready graduates. Australasian Journal of Paramedicine 2015;12(3).

48. Boyle MJ, Wallis J. The glut of graduate paramedics - What do we do with them? ibid. 2015;12(5).

49. McCall L, Wray N, Lord B. Factors affecting the education of pre-employment paramedic students during the clinical practicum. ibid. 2009;7(4).

50. Whyte DG, Madigan V, Drinkwater EJ. Predictors of academic performance of nursing and paramedic students in first year bioscience. Nurse Educ Today 2011;31:849-54.

51.Sahu S, Lata I. Simulation in resuscitation teaching and training, an evidence based practice review. J Emerg Trauma Shock 2010;3:378-84.

52. Weaver A. High-fidelity patient simulation in nursing education: an integrative review. Nurs Educ Perspect 2011;32:37-40.

53. Dickinson T, Hopton J, Pilling M. An evaluation of nursing students' perceptions on the efficacy of high fidelity clinical simulation to enhance their confidence, understanding and competence in managing psychiatric emergencies. J Clin Nurs 2016;25:1476-8.

54. Waycott J, Dalgarno B, Kennedy G, Bishop A. Making science real: photo-sharing in biology and chemistry. Research in Learning Technology 2012;201-14.

55. Williams A. A study of emotion work in student paramedic practice. Nurse Educ Today 2013;33:512-7. 